
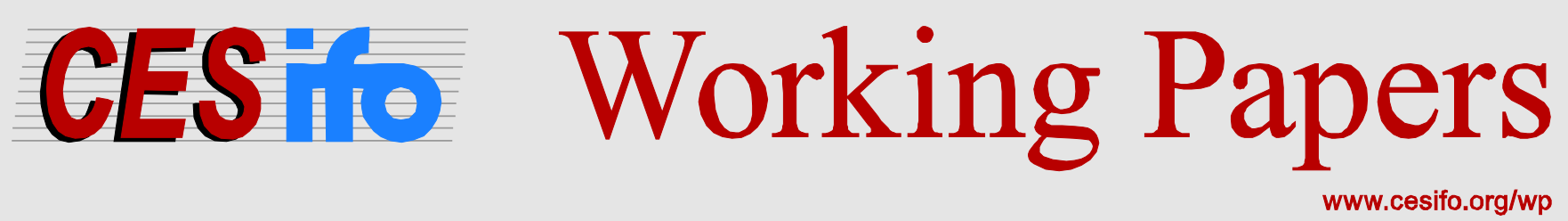

\title{
Competition for Natural Resources and the Hold-Up Problem
}

\author{
Carsten Hefeker \\ Sebastian G. Kessing
}

CESIFO WORKING PAPER No. 6120

CATEgory 2: PuBlic CHOICE

OCTOBER 2016

An electronic version of the paper may be downloaded
- from the SSRN website: $\quad$ www.SSRN.com
- from the RePEc website:
- from the CESifo website: $\quad$ www.RePEc.org

ISSN 2364-1428 


\title{
Competition for Natural Resources and the Hold-Up Problem
}

\begin{abstract}
We study the role of competition for the hold-up problem in foreign direct investment in resource-based industries. The host country government is not only unable to commit not to expropriate investment ex post, but is also unable to commit to the provision of local resources. In the case of competition for local resources this dual commitment problem triggers higher investment levels and increases host country revenues, but hurts pro.ts of international investors.
\end{abstract}

JEL-Codes: F210, F230, Q340.

Keywords: foreign direct investment, natural resources, hold-up problem.

\author{
Carsten Hefeker \\ University of Siegen \\ Department of Economics \\ Unteres Schloss 3 \\ Germany-57068 Siegen \\ carsten.hefeker@uni-siegen.de
}

\author{
Sebastian G. Kessing \\ University of Siegen \\ Department of Economics \\ Unteres Schloss 3 \\ Germany - 57068 Siegen \\ kessing@vwl.wiwi.uni-siegen.de
}

\section{September 2016}

We are grateful for comments from our referees and the associate editor Andrés Carvajal, participants at the European Public Choice Meeting 2014 at Cambridge University, the CESifo Public Sector Conference, and the Natural Resource Governance conference in Siegen, in particular Roberto Bonfatti, Urs Steiner Brandt and Marco Sahm. We thank Artur Grigoryan for excellent research assistance. Sebastian G Kessing thanks the Centre for Business Taxation (CBT) at the University of Oxford and the Centre for Competitive Advantage in the Global Economy (CAGE) at the University of Warwick for their hospitality to carry out this research. 


\section{Introduction}

The sustained growth of emerging economies has substantially increased worldwide demand for natural resources. Not surprisingly, countries that depend on imports of such resources increasingly discuss the issue of resource security, and increased competition for scarce resources has lead to warnings about "resource wars", a "new scramble for Africa" or a "new great game" for access to Central Asian gas and oil (Cooley 2012, Halper 2010, Shambaugh 2013). As a corollary of this development, international firms in natural resource industries from emerging economies have been seeking better access to resources and upstream integration in the form of substantially increased foreign direct investment in resource-rich countries. Governments of host countries have welcomed the arrival of these new investors, whereas international companies from traditional and developed source countries have seen their profitability threatened as these competing investors were moving in. ${ }^{1}$

Investing in natural resources is particularly problematic for international investors in the presence of weak institutions in host countries. Non-renewable resources such as oil, gas or metals are particularly vulnerable to weak property rights because they are usually regionally concentrated, need high expenditures for search and exploration, and take considerable time before they become marketable. This exposes investors to the risk of renegotiation or expropriation, i.e. being hold-up, and this can be regarded as one dimension of the resource curse (Bhattacharyya and Hodler 2010, Sachs and Werner 2001, Bohn and Deacon 2000). Recent prominent cases of conflicts about revenue sharing and outright expropriation of foreign investments in resource-based industries include Repsol in Argentina, Rio Tinto in Guinea and First Quantum Minerals in the Democratic Republic of Congo, which alone are estimated to have cost some $\$ 13 \mathrm{bn}$ (Stevens et al. 2013). The World Bank (2009) lists 30 countries that revised oil contracts and taxation between 1999 and 2010, and Stevens et al. (2013) mention 25 cases in which increases in taxes and royalties were implemented unilaterally. ${ }^{2}$

\footnotetext{
${ }^{1}$ Famous cases of rivalry between foreign firms for access to oil resources are the US-UK conflict between the world wars in the Middle East and Latin America (Venn 1986, Yergin 1991) or the ChineseUS conflict in Central Asia more recently. Maurer (2013), for instance, describes how Peru exploited the conflict between the US and the UK in the 1970s, and Cooley (2012) shows how Kazakhstan exploited the conflict between the US and China after independence. Host governments expropriating and transfering foreign investments to national oil firms, in turn, has a long history with a peak in the 1970s and 1980s and a renewed increase over more recent years (see Hogan et al. 2010, Tomz and Wright 2010, Bremmer and Johnston 2009, Maurer 2013).

${ }^{2}$ Notorious cases where the terms of contracts and agreements have been changed or revoked are Venezuela (Manzano and Monaldi 2010) or Russia (Gustafson 2012). As Engel and Fischer (2010) report, however, also countries like the US, Canada, Australia and the UK have "renegotiated" contracts and
} 
The hold-up problem in foreign direct investment has been analyzed extensively, starting with the seminal analysis of Eaton and Gersovitz (1983). Thomas and Worall (1994), Doyle and van Wijnbergen (1994), Svensson (1998), Schnitzer (1999), Konrad and Lommerud (2002), Kessing et al. (2007, 2008, 2009), Stroebel and von Benthem (2013) among others, have discussed various factors affecting the interaction between foreign investors and host country governments and addressed the question how the hold-up problem may be overcome and how optimal contracts may look like. These existing studies of the hold-up problem only consider host governments which cannot commit themselves not to take the lion's share of the returns of an investment and/or the invested capital after a foreign investor has irrevocably invested in a host country. Moreover, in this traditional formulation the hold-up problem is independent of the competition between investors, and is therefore not suitable to analyze the potential effects of increased competition for natural resources on investment, host government revenues and profitability.

In this study, we provide a new insight that makes it possible to understand the role of competition between foreign investors. It is based on the observation that host countries can not only directly increase taxes on foreign profits or expropriate foreign investors, they can also "renegotiate" contracts, revise concessions and restrict the amount of resources that a particular investor is allowed to exploit. In a resource-based industry, a key determinant of an investor's returns is the actual access to local resources.

Consider the investment in drilling equipment and transportation infrastructure in a given oil field. The profitability of this investment will not only be determined by the capital investment, the technical and managerial expertise deployed in the host country, and the tax and royalty payments, but will depend crucially on the investor's right to exploit this specific field. While a host government may grant such rights before the investment is carried out, just as it may promise abstaining from nationalization and confiscatory taxation in the traditional formulation of the hold-up problem, such promises may not be time-consistent. After the investment is sunk, it may be in the host country's interest to renege on the granted rights to exploit local resources, and instead grant these rights to another interested party, such as another foreign investor or a domestic, possibly state-owned, firm. Since capital is sunk, the investor cannot recoup his investment, and although the investment is not touched and no expropriation is taking place, it becomes useless. What the investor can do, however, is to withdraw his technical expertise, leaving the host country with potentially lower output from given capital investments and resources.

imposed windfall taxes or increased royalties in the natural resource sector. 
We study this additional commitment problem and how it interacts with the potential existence of alternative international investors. We demonstrate that the existence of alternative foreign investors substantially changes the interaction between foreign investors and the host government. Intuitively, the presence of competing firms provides an alternative for the host government to put the natural resource to economic use. Given the host country's inability to commit, this drags investors into over-investing to secure the provision of local resources. This unambiguously benefits the host country and hurts foreign investors. Contrary to the classic hold-up problem of taking too much ex post, which typically has negative consequences for the host country, the inability to commit to provide local resources can benefit host countries if there is more than a single use for local resources. Thus, contrary to the standard hold-up approach, our formulation can generate important effects of competition for natural resources in countries with weak governance, which are in line with the empirical evidence and the cases discussed above. ${ }^{3}$

Our study contributes to the vast literature on expropriation of sunk investment already mentioned, but adding the ex-post provision of local resources as an important new dimension of the problem. The analysis relates to Janeba (2000), who shows that foreign investors can overcome the hold-up problem by investing in excess capacity in an alternative location. This threatens the host government with a shift in economic activity in case of ex post confiscatory taxation. In our analysis, the existence of a competing investor provides an alternative possibility to put local resources to productive use and thereby serves a similar end for the host government, triggering higher investment.

Finally, our study adds an important aspect to the literature on resource nationalism and the scramble for resources. It is often argued that in particular China is trying to secure monopolistic access to resources, mostly in Africa. The argument put forward for this is that by securing a monopoly on such resources, China could improve its termsof-trade (see Bonfatti 2009). ${ }^{4}$ We add another view to this argument by showing that restricted access would increase the profits that a monopolistic investor could make. A restriction of competition from other investors would thus directly shift more profits to the investor, independent from potential terms-of-trade considerations.

\footnotetext{
${ }^{3}$ Note that setting up a domestic, resource-extracting firm may serve a similar purpose as a second foreign investor. This also provides an alternative for the domestic government to put its resources to economic use, and can accordingly also generate incentives for foreign investors to increase investment in order to receive better access to local resources in the absence of commitment.

${ }^{4}$ In particular the popular press often claims that China aims at securing and then exploiting a monopolistic position. It is disputed, however, whether this is really the case (Moran 2010).
} 


\section{Foreign investment in natural resources}

In what follows we develop a model to illustrate a stylized story of foreign investment, the risk of expropriation, the allocation of resources to be combined with the capital stock, and technical expertise provided by the investor. We think of this as a foreign firm that invests in a resource rich country, for instance in drilling equipment, a mine, or an oil or gas pipeline to exploit those resources. This revenue from this investment is subject to ex-post expropriation after the investment has been sunk. Expropriation can be full or partial in the sense that tax arrangements or profit-sharing agreements can be broken. This gives rise to the standard hold-up problem.

The second hold-up problem is that the host country's government can renege on the concession and access to the resource by, for instance, not supplying the pipeline or blocking access to the mine or oil or gas field. We assume that there is fixed amount of exploitable resources, such as an oil field, to which the host countries grants access because it is unable to exploit the resource on its own, either because it is capital-constrained or lacks the necessary technical expertise. With a competing investor, however, the country can renege on its promise to grant access and instead shift the right of access to another investor who can provide the necessary additional expertise.

Lastly, the investors have to decide how much effort to provide after capital has been invested and access to resources has been given. We think of this as, for instance, sending qualified personal or additional (non-sunk) technical equipment to operate the initially invested equipment. Extraction of the resource depends critically on this additional effort by the investor and is impossible without it.

As our benchmark, we first show that, with commitment, for a given amount of domestic resources it does not matter for total investment, output and tax revenues whether a single, or two competing foreign investors are present in the host country. We then contrast the differential outcome between the single investor case and the case of two competing investors without commitment to show how this will lead to higher investment, higher output, higher government revenues and lower profits for foreign investors. Finally, we can compare total investment and tax revenues with and without commitment. This allows us to show that the positive effect of competition on investment without commitment can dominate the negative effect of the absence of commitment and can result in higher total investment and tax revenues. 


\subsection{The basic framework}

We start by considering a resource-based industry which relies on foreign investors, denoted by subscript $i$, to bring in capital and expertise to process the natural resource in the host country. For both scenarios, full commitment and the lack thereof, we contrast two cases. Either there is only a single foreign investor, $i=s$, or, alternatively, there are two competing investors $i=1,2$ present in the host country. Total output of investor $i$ is produced according to the constant returns to scale production function $f\left(k_{i}, m_{i}, z_{i}\right)$, with the usual properties $\frac{\partial f}{\partial q}>0, \frac{\partial^{2} f}{\partial q}<0, \frac{\partial^{2} f}{\partial q \partial l}>0, q=k_{i}, m_{i}, z_{i}$, and $l=k_{i}, m_{i}, z_{i}$, and $q \neq l$, where capital investment $k_{i}$, the local natural resource $m_{i}$, and technical and business expertise $z_{i}$ are the factors of production. For our results, we make the assumption that technology is of the Cobb-Douglas form, i.e. $f\left(k_{i}, m_{i}, z_{i}\right)=k_{i}^{\alpha} m_{i}^{\beta} z_{i}^{\gamma}, 0<\alpha, \beta, \gamma<1$, $\gamma=1-\alpha-\beta$. For the exposition of the model we use a more general formulation, since the dynamics and the strategic interaction are better visible. The formal results and their extensive derivation using the Cobb-Douglas assumption are relegated to the Appendix. Factor costs, $r$ (for capital $k_{i}$ ) and $w$ (for non-resource input $z_{i}$ ) are given, constant and equal for all investors. Output is sold in the world market at an exogenous price of one.

Capital investment is sunk once deployed in the host country and, without commitment, subject to confiscatory taxation ex post. Similar to Janeba (2000), we do not explicitly study repeated interaction. However, the investor also provides his technical and business expertise $z_{i}$, and can adjust this input depending on his tax burden $t_{i}$ and the amount of local resources $m_{i}$ allocated to him. The possibility to adjust another factor of production does not eliminate the hold-up problem entirely but alleviates it.

We assume that taxation takes the form of a specific tax $t_{i}$ per unit of output that is applied uniformly to all foreign investors. This amounts to a situation where the host country charges an excise on output, such as, for example, the number of barrels of oil exported. In many real world contracts, the pro rata payments are complemented by a lump sum up-front payment (Hogan et al. 2010). Such a payment could be easily added into our analysis without changing the results.

The upfront investment may be interpreted narrowly to include only capital in the actual business venture. Alternatively, it may be interpreted more widely to also include other investments made by foreign investors into the local infrastructure, which is often the case with Chinese investments in Africa (Brautigam 2009, Economy and Levi 2014). Similarly, the local resource provided by the host government may be interpreted narrowly as access to natural resources, or more widely to additionally include inputs provided 
by the host government such as administrative and legal support or publicly provided infrastructure whose use can be restricted. Importantly, the host government may not be able to commit ex ante on the level of this input. In addition, only an exogenous level of these resources $m$ is available. Treating the overall level of $m$ as fixed can either be justified by the fact that the total amount of the available non-renewable resources is limited by nature. Alternatively, it may be interpreted as the maximum level of the natural resource that can be processed within a given time period, where the local government does not inter-temporally optimize the exploitation of its resource. ${ }^{5}$

We contrast the commitment case, where the government can commit to tax rates and the allocation of domestic resources ex ante, and the no commitment case, where it cannot. Moreover, we consider the differences between the case of a single investor and the case of two competing investors in each of these cases. The latter situation is called the competing investor case or the competition case. In this competition case, we assume throughout that the two investors take their decisions non-cooperatively. In the absence of government commitment both firms use their up-front investment to affect the government's decision how to allocate the domestic resources between investors since their profits depend on the share of resources that they receive. Finally, we assume that firms are symmetric and focus on the symmetric equilibrium.

The stages of the game differ between the commitment and the no-commitment case. The timing under commitment is as follows: in stage 1, the host government commits to a tax rate/tax rates $t_{i}$ and to the allocation of the natural resource $m_{i}$ to either a single investor or how it shares access to it among competing investors. In stage 2, the foreign investor/investors decides/decide about capital investment and about the complementary input $z_{i}$. Without commitment there are three stages in the game. Their sequence is as follows. In stage 1 the investor/the investors decides/decide how much capital $k_{i}$ to invest, and this capital is sunk. In the case of two competing investors they decide simultaneously. In stage 2 , the host government government sets a tax rate/tax rates $t_{i}$ and decides on the allocation of the natural resource $m_{i}$. Finally, in stage three, the investor/the investors decides/decide on the level of the complementary input $z_{i}$, and tax revenues and net-of tax profits are then realized.

\footnotetext{
${ }^{5}$ This may be due to the fact that the local non-benevolent government is facing a high probability of losing power and aims at maximizing its revenue over a short time horizon (Robinson et al. 2006, Svensson 1998).
} 


\section{$2.2 \quad$ Full commitment}

As our benchmark, we first analyze the case in which the host government can fully commit on the level of taxation and the amount of resources made available to each foreign investor. We focus on the difference between the single investor case and the case of two competing investors, since our main interest is to identify the differential effect between these two cases in the absence of commitment. We summarize our benchmark finding:

Proposition 1 In a symmetric equilibrium with competing investors which produce using a Cobb-Douglas technology, total factor inputs, total output, the tax rate, total tax revenues, and total after tax profits are equal to the single investor case, if the government can commit to its policy.

Proof. See Appendix.

Intuitively, under commitment, the decision problem of each individual investor is structurally equivalent to that of a single investor, given a certain level of local resources provided to the investor and given the level of taxation. The host government divides the local resource arbitrarily between investors and chooses the same tax rate as with a single investor to maximize its revenue. Given the constant returns to scale technology, the aggregate inputs of all investors equal the total inputs of the single investor. ${ }^{6}$ Accordingly, total output is equal in both cases as well as total tax revenues and total after-tax profits. The bottom line is that under commitment it makes no difference whether the host government deals with a single or multiple investors. Finally, note that, under commitment, our restriction on the set of admissible contracts prevents an efficient investment level, since the linear tax distorts the investment decision. If we allowed for more general contracts, i.e. a contract specifying the efficient input levels of $k_{i}$ and $z_{i}$ and a lump-sum payment to the investor that allowed him to break even, efficiency could be achieved. However, also in this case, the efficient outcome is independent of the number of investors.

\subsection{No commitment: A single investor}

We consider first the case of a single investor. The sequence of events without commitment is as follows. At stage 1, the investor decides how much capital to invest in the host

\footnotetext{
${ }^{6}$ This result is not restricted to the Cobb-Douglas technology but can be derived for any constant returns technology. We focus on the Cobb-Douglas case for consistency with our further propositions below.
} 
country. At stage 2, the host country government chooses the tax rate $t_{s}$ on revenues and allocates the local resource $m$. At stage 3 , the investor chooses the additional factor input level $z_{s}$. Solving backwards, at stage 3 , the investor chooses his input to

$$
\max _{z_{s}} \pi_{s}=\left(1-t_{s}\right) f\left(k_{s}, m_{s}, z_{s}\right)-w z_{s}
$$

with first order condition

$$
\left(1-t_{s}\right) \frac{\partial f}{\partial z_{s}}=w
$$

which implicitly defines $z_{s}^{*}=z_{s}^{*}\left(t_{s}^{*}, k_{s}^{*}, m_{s}^{*}\right)$.

At stage 2 , the host country government decides on $t_{s}$ and $m_{s}$. We assume that it maximizes revenue. This can be motivated by a non-benevolent government, but it is also fully compatible with welfare maximization since output is sold in the world market and the foreign investor's profits accrue to non-local residents. Since the host country has no alternative use for the local resource without the foreign investment, it sets $m_{s}^{*}=m$. The government's problem with respect to the optimal ex post taxation then is to

$$
\max _{t_{s}} R_{s}=t_{s} f\left(k_{s}, m, z_{s}^{*}\left(t_{s}, k_{s}, m\right)\right)
$$

with first order condition

$$
f\left(k_{s}, m, z_{s}^{*}\left(t_{s}, k_{s}\right)\right)+t_{s} \frac{\partial f}{\partial z_{s}^{*}} \frac{\partial z_{s}^{*}}{\partial t_{s}}=0
$$

which implicitly defines $t_{s}^{*}=t_{s}^{*}\left(k_{s}\right)$.

At stage 1 , the single investor chooses $k_{s}$ to maximize

$$
\max _{k_{s}} \pi_{s}=\left(1-t_{s}^{*}\left(k_{s}\right)\right) f\left(k_{s}, m, z_{s}^{*}\left(m, t_{s}^{*}\left(k_{s}\right), k_{s}\right)\right)-r k_{s}
$$

with first order condition

$$
-f\left(k_{s}, m, z_{s}^{*}\right) \frac{\partial t_{s}^{*}}{\partial k_{s}}+\left(1-t_{s}^{*}\right)\left[\frac{\partial f}{\partial k_{s}}+\frac{\partial f}{\partial z_{s}^{*}}\left(\frac{\partial z_{s}^{*}}{\partial k_{s}}+\frac{\partial z_{s}^{*}}{\partial t_{s}^{*}} \frac{\partial t_{s}^{*}}{\partial k_{s}}\right)\right]=r .
$$

The investor equates the direct marginal effect on net profits, the indirect effect on net profits via the corresponding adjustment of the additional input, and the indirect marginal effect from the resulting adjustment of the tax rate with the opportunity cost of capital. 


\subsection{No commitment: Competing investors}

Consider now the case where the host country admits two investors $i=1,2$ into the country. The sequence of events is as in the single investor case. At stage 3 , both investors decide on $z_{i}$ with first order conditions analogous to (1). At stage 2 the government now needs to decide how to allocate the total amount of resources available $m$ between the two firms, with share $m_{i}$ each, and to choose the tax rates $t_{1}$ and $t_{2}$ that are levied on the investors' output. The government's problem is thus

$$
\max _{t_{1}, t_{2}, m_{1}} R_{c}=t_{1} f\left(k_{1}, m_{1}, z_{1}^{*}\left(t_{1}, m_{1}\right)\right)+t_{2} f\left(k_{2}, m-m_{1}, z_{2}^{*}\left(t_{2}, m-m_{1}\right)\right)
$$

where we have substituted the resource constraint $m_{1}+m_{2}=m$. The solution to this problem is characterized by

$$
\begin{gathered}
f\left(k_{i}, m_{i}, z_{i}^{*}\right)+t_{i} \frac{\partial f}{\partial z_{i}^{*}} \frac{\partial z_{i}^{*}}{\partial t_{i}}=0, \text { for } i=1,2, \text { and } \\
t_{1}\left[\frac{\partial f}{\partial m_{1}}+\frac{\partial f}{\partial z_{1}^{*}} \frac{\partial z_{1}^{*}}{\partial m_{1}}\right]=t_{2}\left[\frac{\partial f}{\partial m_{2}}+\frac{\partial f}{\partial z_{2}^{*}} \frac{\partial z_{2}^{*}}{\partial m_{2}}\right]
\end{gathered}
$$

where condition (5) illustrates how the host government allocates local resources between the two competing investors such that the resulting marginal tax revenue is equalized across investors. Since the host government participates in the firms' revenue with shares $t_{1}^{*}$ and $t_{2}^{*}$, respectively, it is in its interest to maximize total output by allocating the resources efficiently between the firms whenever $t_{1}^{*}=t_{2}^{*}$.

In stage 1 both firms simultaneously decide on their investment $k_{i}$, solving

$$
\max _{k_{i}} \pi_{i}=\left(1-t_{i}^{*}\left(k_{i}\right)\right) f\left(k_{i}, m_{i}^{*}\left(k_{i}\right), z_{i}^{*}\left(k_{i}, m_{i}^{*}\left(k_{i}\right), t_{i}^{*}\left(k_{i}\right)\right)\right)-r k_{i}
$$

with first order condition

$$
-\frac{\partial t_{i}^{*}}{\partial k_{i}} f(.)+\left(1-t_{i}^{*}\right)\left[\frac{\partial f}{\partial k_{i}}+\frac{\partial f}{\partial z_{i}^{*}}\left(\frac{\partial z_{i}^{*}}{\partial k_{i}}+\frac{\partial z_{i}^{*}}{\partial t_{i}^{*}} \frac{\partial t_{i}^{*}}{\partial k_{i}}\right)+\frac{\partial m_{i}^{*}}{\partial k_{i}}\left(\frac{\partial f}{\partial m_{i}^{*}}+\frac{\partial f}{\partial z_{i}^{*}} \frac{\partial z_{i}^{*}}{\partial m_{i}^{*}}\right)\right]=r
$$

for $i=1,2$. For both investors, adding an additional unit of capital may change the level of taxation. Moreover, there are now three effects of an additional unit of capital on after tax profits as can be seen by the terms in squared brackets on the left hand side of (6). First, the direct effect and the indirect effect via the adjustment of $z_{i}^{*}$ are analogous to the single investor case. Second, there is now an additional strategic effect, which results from the response of the host government to reallocate the available local resources across 
investors. The latter consists of a direct effect and an indirect effect stemming from the increased leverage of adjusting the complementary input. The first order conditions (6) implicitly define the investors' best responses vis-à-vis each other, $k_{1}^{*}\left(k_{2}\right)$ and $k_{2}^{*}\left(k_{1}\right)$.

Without commitment the question arises whether the host government could also be tempted not only to shift domestic resources between investors or to increase taxes ex post, but to also expropriate one investor and shift this capital stock to the other investor. We have not allowed for this possibility, but it is straightforward to see that this is not a binding restriction in our model. In fact, the government can never increase its tax revenues from such an action, since total production and thus tax revenues will not be increased from such an action under constant returns to scale.

\subsection{Comparison}

We can now study the differential effects of competing investors relative to the situation with a single investor. First, we consider the overall level of investment.

Proposition 2 Let technology be of the Cobb-Douglas type. Then, without commitment, there exists a unique symmetric equilibrium, in which we have $k_{i}^{*}>k_{s}^{*} / 2$ for each individual investor, and total investment is higher than in the single investor case, i.e. $\sum_{i=1,2} k_{i}^{*}>k_{s}^{*}$.

Proof. See Appendix.

As we show in the Appendix, the comparative statics are straightforward with CobbDouglas technology. In particular, $\frac{\partial t_{i}^{*}}{\partial k_{i}}=0$, which implies that the equations (3) and (6), which determine the investment in both cases, simplify substantially. Moreover, $\frac{\partial m_{i}^{*}}{\partial k_{i}}>0$, i.e. increased investment results in a higher share of domestic resources allocated to the investor by the host government. Intuitively, since the host government cannot commit to the provision of resources, both investors can affect the allocation of local resources in their favor through their investment. Since the host country participates in the overall production via ex post taxation, additional investment, which increases overall output, is a suitable instrument to affect the distribution of resources in the respective investor's direction. Of course, in the symmetric equilibrium, the strategic effects of additional investment cancel out, and both investors receive only half of the available resources. ${ }^{7}$

We turn now to the effect of competition on tax revenues.

\footnotetext{
${ }^{7}$ The situation is structurally similar to a non-perfectly discriminating contest, see Konrad (2009). Both investors make sunk investments to receive a higher share of domestic resources, analogous to exerting higher contest effort to increase the own probability of obtaining the contested prize. The only difference is that in our case the domestic resource can be continuously divided between the investors.
} 
Proposition 3 With Cobb-Douglas technology, tax revenues are higher with competing investors.

Proof. According to Proposition 2 both firms together choose a higher level of investment. Moreover, with Cobb-Douglas technology the host government chooses the same tax rate as in the single investor case. Given the same tax rate and higher total investment both investors choose a level of $z_{i}^{*}$, so that $\sum_{i=1,2} z_{i}^{*}>z_{s}^{*} / 2$. Thus, total output increases and government revenues, which are a fixed fraction of that, must also increase.

This result shows that the host government unambiguously profits from increased competition. With competing investors, and a production that relies on domestic inputs controlled by the government, the inability to commit turns into a strategic advantage for the host government. ${ }^{8}$

Next, we consider profits.

Proposition 4 Given Cobb-Douglas technology, total profits in the single investor case are higher than aggregate profits in the multiple investor case, i.e. $\pi_{s}^{*}>\sum_{i=1,2} \pi_{i}^{*}$.

Proof. The single investor could choose an alternative, higher level of investment $\tilde{k}_{s}=\sum_{i=1,2} k_{i}^{*}$. This would result in the same level of taxes as in the competing investors case and the same overall level of additional factor inputs. Accordingly, output and after tax profits would equal $\sum_{i=1,2} \pi_{i}^{*}$. The fact that this level of investment is not chosen by a single investor reveals that total profits are lower in the competing investors case.

The result shows how competition for local resources not only induces higher investment, but that increased investment hurts the firms relative to the single investor case.

Our Propositions 2-4 rely crucially on the inability of the government to commit ex ante on the available level of local resources. If the production function did not require $m$ as a factor of production, the hold-up problem would only consist of the host government setting excessively high taxes after investors have irrevocably invested. In this case, there would be no strategic interaction between investors. Thus, the inability to commit "to give" has specific implications that are not present in the traditional hold-up situation where the government only cannot commit "not to take". Only by taking these additional considerations into account it is possible to understand the effects of competition for the

\footnotetext{
${ }^{8}$ Note that an increased investment level is typically sufficient for this result, even if the tax rate is not independent as in the Cobb-Douglas case. The government can always choose the same level and would realize a higher revenue level than with a single investor. It will change the tax level only if this will increase its revenue.
} 
overall level of investment, tax revenues and profitability in resource based-industries in countries with weak property rights protection.

Finally, the assumption of Cobb-Douglas technology allows us to explicitly solve for total investment with and without commitment. While the investment level will obviously always be higher under commitment with a single investor, this is less evident with multiple investors. In this case the second hold-up problem with respect to providing the domestic resources, which triggers higher investments, may overcompensate the hold-up problem with respect to ex-post taxation. This possibility is stated in Proposition 5.

Proposition 5 With Cobb-Douglas technology total investment with two competing investors, and tax revenues can be higher without commitment than with commitment.

Proof. See Appendix.

As we show in the Appendix, this is more likely to happen when the domestic resource is more important for production. Intuitively, the strategic over-investment effects are particularly strong in this case, and they can overcompensate the higher level of ex-post confiscatory taxation.

\section{Conclusion}

Our main argument is that the competition for access to natural resources in an uncertain legal environment gives rise to a "second" hold-up problem. Not only do international investors suffer the standard risk of being taxed beyond initial agreement or being expropriated, but they also face the risk of denied access to local resources. This risk depends on the competition between foreign investors and the scope of the host government to shift domestic resources to competitors. Competition for natural resources helps host countries with weak property rights protection to induce higher investment in the absence of commitment. Our approach, we would argue, is particularly relevant for the recent surge in natural resources-related foreign investments by investors from emerging countries. After all, firms from traditional "Western" countries have been competing with each other for access to natural resources in developing countries for many decades (Venn 1986, Yergin 1991). However, the problem as analyzed above may be less relevant for such investors. These investors may turn for help to the legal system in their home countries and pursue formal or informal action against other investors who are benefiting from the re-allocation of local resources by the host government (Joffé et al. 2009). Such measures are likely to 
be particularly effective where international investors have business interests and tangible property in the home countries of those competing firms, facilitating collusion among them. ${ }^{9}$

In the case of competing investors from emerging countries, however, such action is much less effective, since these new source countries themselves have weaker protection of foreign investment and often no unbiased access to the legal system. Moreover, investors from these countries typically have less developed business interests and fewer assets in OECD countries, and are thus less vulnerable to defensive legal action. The scope for suitable actions by an investor from a traditional source country who is negatively affected by a decision of a host country to reallocate access to natural resources or other essential local inputs to a rival from an emerging country is thus more limited compared to actions against a traditional competitor.

Our framework captures the latter situation and is accordingly well suited to explain why the recent expansion of foreign direct investment in resource-based and resourceextracting industries in countries with weak governance is perceived to threaten the profitability of investments by traditional investors. It is also in line with the observation that the arrival of this new class of investors has been very welcome to the rulers of resource rich host countries. In the light of these arguments, the position of multinationals from OECD countries in the competition for natural resources in developing countries may benefit from stronger governance in emerging countries and from higher levels of business activities of the emerging investors in the traditional source countries.

\section{Appendix}

\subsection{Proof of Proposition 1}

With Cobb-Douglas technology production is given by $f\left(k_{i}, m_{i}, z_{i}\right)=k_{i}^{\alpha} m_{i}^{\beta} z_{i}^{\gamma}$, with $\gamma=$ $1-\alpha-\beta, 0<\alpha, \beta, \gamma<1$, and $i=1,2, s$. The subscript $s$ denotes the single investor case, the subscripts $i=1,2$ refer to individual investors in the case with two investors. Under commitment, the government first chooses the tax rate(s) $t_{i}$ and the division of the local resource among investors $m_{i}$. The firm(s) then choose(s) investment $k_{i}$ and the complementary input $z_{i}$. Consider first the case of a single investor. Solving backwards,

\footnotetext{
${ }^{9}$ Also, there might be a direct involvement of the home governments of competing international firms and a political solution for those conflicts. A famous case for this is the separation of spheres of influence and exclusive access to the Middle East oil fields between the US and the UK up to the 1950s (Venn 1986).
} 
the investor maximizes its profits

$$
\max _{k_{s}, z_{s}} \pi=\left(1-t_{s}\right) k_{s}^{\alpha} m_{s}^{\beta} z_{s}^{\gamma}-r k_{s}-w z_{s}
$$

with first order conditions

$$
\begin{aligned}
\frac{\partial \pi}{\partial k_{s}} & =(1-t) \alpha m^{\beta} z^{\gamma} k^{-(1-\alpha)}-r=0 \\
\frac{\partial \pi}{\partial z_{s}} & =(1-t) \gamma m^{\beta} z^{-(\alpha+\beta)} k^{\alpha}-w=0
\end{aligned}
$$

which yield $k_{s}^{*}=\left[(1-t)\left[\frac{\alpha}{r}\right]^{\alpha+\beta}\left[\frac{\gamma}{w}\right]^{\gamma}\right]^{\frac{1}{\beta}} m$, and $z_{s}^{*}=\left[(1-t)\left[\frac{\alpha}{r}\right]^{\alpha}\left[\frac{\gamma}{w}\right]^{1-\alpha}\right]^{\frac{1}{\beta}} m$. At the first stage the government chooses $m_{s}=m$ and maximizes $R=t_{s} k^{\alpha} m^{\beta} z^{1-\alpha-\beta}$ by its choice of $t_{s}$ which gives $t_{s}^{*}=\beta$. Substituting, the optimal factor inputs are

$$
\bar{k}_{s}^{*}=\left[(1-\beta)\left[\frac{\alpha}{r}\right]^{\alpha+\beta}\left[\frac{\gamma}{w}\right]^{\gamma}\right]^{\frac{1}{\beta}} m, \text { and } \bar{z}_{s}^{*}=\left[(1-\beta)\left[\frac{\alpha}{r}\right]^{\alpha}\left[\frac{\gamma}{w}\right]^{1-\alpha}\right]^{\frac{1}{\beta}} m \text {. }
$$

For notational purpose we have added the bar over the equilibrium factor inputs with commitment to distinguish these variables from the outcomes derived for the non-commitment case below. With two investors both firms maximize $\pi_{i}=\left(1-t_{i}\right) k_{i}^{\alpha} m_{i}^{\beta} z^{\gamma}-r k_{i}-w z_{i}$ by choosing $k_{i}$ and $z_{i}$ with first order conditions

$$
\begin{aligned}
\frac{\partial \pi}{\partial k_{i}} & =\left(1-t_{i}\right) \alpha m_{i}^{\beta} z_{i}^{\gamma} k_{i}^{\alpha-1}-r=0 \\
\frac{\partial \pi}{\partial z_{i}} & =\left(1-t_{i}\right) \gamma m_{i}^{\beta} z_{i}^{-\alpha-\beta} k_{i}^{\alpha}-w=0
\end{aligned}
$$

so that $\bar{k}_{i}^{*}=\left[\left(1-t_{i}\right)\left[\frac{\alpha}{r}\right]^{\alpha+\beta}\left[\frac{\gamma}{w}\right]^{\gamma}\right]^{\frac{1}{\beta}} m_{i}$ and $\bar{z}_{i}^{*}=\left[\left(1-t_{i}\right)\left[\frac{\alpha}{r}\right]^{\alpha}\left[\frac{\gamma}{w}\right]^{1-\alpha}\right]^{\frac{1}{\beta}} m_{i}, i=1,2$.

Note that both are linear in $m_{i}$. The host government's problem is

$$
\begin{array}{r}
\max _{t_{1}, t_{2}, m_{1}} R=t_{1}\left[\left[\left(1-t_{1}\right)\left[\frac{\alpha}{r}\right]^{\alpha+\beta}\left[\frac{\gamma}{w}\right]^{\gamma}\right]^{\frac{1}{\beta}} m_{1}\right]^{\alpha} m_{1}^{\beta}\left[\left[\left(1-t_{i}\right)\left[\frac{\alpha}{r}\right]^{\alpha}\left[\frac{\gamma}{w}\right]^{1-\alpha}\right]^{\frac{1}{\beta}} m_{1}\right]^{\gamma} \\
+t_{2}\left[\left[\left(1-t_{2}\right)\left[\frac{\alpha}{r}\right]^{\alpha+\beta}\left[\frac{\gamma}{w}\right]^{\gamma}\right]^{\frac{1}{\beta}}\left[m-m_{1}\right]\right]^{\alpha}\left[m-m_{1}\right]^{\beta}\left[\left[\left(1-t_{i}\right)\left[\frac{\alpha}{r}\right]^{\alpha}\left[\frac{\gamma}{w}\right]^{1-\alpha}\right]^{\frac{1}{\beta}}\left[m-m_{1}\right]\right]^{\gamma} .
\end{array}
$$

The first order conditions with respect to $t_{1}$ and $t_{2}$ are

$$
\left(1-t_{i}\right)^{\frac{1-\beta}{\beta}}-t_{i} \frac{1-\beta}{\beta}\left(1-t_{i}\right)^{\frac{1-\beta}{\beta}-1}=0, i=1,2
$$


so that $t_{i}^{*}=\beta, i=1,2$. Moreover, government revenue is linear in $m$, such that any split of the local resource is optimal. Assume that the government arbitrarily splits the resource, allocating a share $\theta_{1}$ to firm 1 , and a share $\theta_{2}=1-\theta_{1}$ to firm 2 . Total investment is

$$
\begin{aligned}
\sum_{i=1,2} \bar{k}_{i}^{*} & =\left[(1-\beta) \alpha^{\alpha+\beta} w^{-\gamma} \gamma^{\gamma} r^{-(\alpha+\beta)}\right]^{\frac{1}{\beta}} \theta_{1} m+\left[(1-\beta) \alpha^{\alpha+\beta} w^{-\gamma} \gamma^{\gamma} r^{-(\alpha+\beta)}\right]^{\frac{1}{\beta}}\left(1-\theta_{1}\right) m \\
& =\left[(1-\beta) \alpha^{\alpha+\beta} w^{-\gamma} \gamma^{\gamma} r^{-(\alpha+\beta)}\right]^{\frac{1}{\beta}} m=\bar{k}_{s}^{*} .
\end{aligned}
$$

Total investment is independent of the number of investors under commitment. Likewise $\sum \bar{z}_{i}^{*}=\bar{z}_{s}^{*}$. Thus, depending on the split of $m$, the investors' factor inputs will be split in the same proportion and total factor inputs are equal to the single investor case. Given the constant returns to scale property of the Cobb-Douglas technology total output is the same with a single investor or two competing investors. Finally, given that the tax rate is the same in both cases, total tax revenues are also equal.

\subsection{Proof of Proposition 2}

Consider first the single investor case without commitment. Solving backwards, the single investor's chooses $z_{s}$ at stage 3 to maximize $\pi_{s}=\left(1-t_{s}\right) k_{s}^{\alpha} m_{s}^{\beta} z^{\gamma}-w z_{s}$, with solution $z_{s}^{*}=\left[\left(1-t_{s}\right) \gamma k_{s}^{\alpha} m_{s}^{\beta} w^{-1}\right]^{\frac{1}{\alpha+\beta}}$. At stage 2 the government maximizes $R=t_{s} k_{s}^{\alpha} m_{s}^{\beta} z_{s}^{\gamma}=$ $t_{s} k_{s}^{\alpha} m^{\beta}\left[\left(1-t_{s}\right) \gamma k_{s}^{\alpha} m^{\beta} w^{-1}\right]^{\frac{\gamma}{\alpha+\beta}}$ by its choice of $t_{s}$, where we have already substituted $m_{s}=m$ as the optimal allocation of the domestic resource. The solution to this problem yields $t_{s}^{*}=\alpha+\beta$. Substituting we have $z_{s}^{*}=\left[\gamma^{2} k_{s}^{\alpha} m^{\beta} w^{-1}\right]^{\frac{1}{\alpha+\beta}}$. At stage 1 the single investor then chooses $k_{s}$ to maximize $\pi_{s}=\gamma k_{s}^{\alpha} m_{s}^{\beta}\left[\gamma^{2} w^{-1} k_{s}^{\alpha} m_{s}^{\beta}\right]^{\frac{\gamma}{\alpha+\beta}}-r k_{s}$, with solution $k_{s}^{*}=A\left[\frac{\alpha}{\alpha+\beta}\right]^{\frac{\alpha+\beta}{\beta}}$, where $A \equiv\left[r^{-(\alpha+\beta)} \gamma^{1+\gamma} w^{-\gamma}\right]^{\frac{1}{\beta}} m$.

For comparison of this investment level we now solve the competing investor case. At the third stage both firms maximize $\pi_{i}=\left(1-t_{i}\right) k_{i}^{\alpha} m_{i}^{\beta} z_{i}^{\gamma}-w z_{i}$ by choice of $z_{i}$, which yields $z_{i}^{*}=\left[\left(1-t_{i}\right) \gamma k_{i}^{\alpha} m_{i}^{\beta} w^{-1}\right]^{\frac{1}{\alpha+\beta}}, i=1,2$. The government's problem in stage 2 is

$$
\begin{aligned}
\max _{t_{1}, t_{2}, m_{1}} R= & t_{1} k_{1}^{\alpha} m_{1}^{\beta} z_{1}^{\gamma}+t_{2} k_{2}^{\alpha} m_{2}^{\beta} z_{2}^{\gamma}=t_{1} k_{1}^{\alpha} m_{1}^{\beta}\left[\left[\left(1-t_{1}\right) \gamma k_{1}^{\alpha} m_{1}^{\beta} w^{-1}\right]^{\frac{1}{\alpha+\beta}}\right]^{\gamma}+ \\
& t_{2} k_{2}^{\alpha}\left[m-m_{1}\right]^{\beta}\left[\left[\left(1-t_{2}\right) \gamma k_{2}^{\alpha}\left[m-m_{1}\right]^{\beta} w^{-1}\right]^{\frac{1}{\alpha+\beta}}\right]^{\gamma} .
\end{aligned}
$$


The first order conditions are

$$
\begin{aligned}
& {\left[\left[\left(1-t_{i}\right)\right]^{\frac{\gamma}{\alpha+\beta}}-t_{i} \frac{\gamma}{\alpha+\beta}\left[\left(1-t_{i}\right)\right]^{\frac{\gamma}{\alpha+\beta}-1}\right] }=0, i=1,2 \\
& k_{1}^{\frac{\alpha}{\alpha+\beta}} t_{1}\left[\left(1-t_{1}\right) \gamma\right]^{\frac{\gamma}{\alpha+\beta}} m_{1}^{\frac{-\alpha}{\alpha+\beta}}-k_{2}^{\frac{\alpha}{\alpha+\beta}} t_{2}\left[\left(1-t_{2}\right) \gamma\right]^{\frac{\gamma}{\alpha+\beta}}\left[m-m_{1}\right]^{\frac{-\alpha}{\alpha+\beta}}=0 .
\end{aligned}
$$

From these we have $t_{1}=t_{2}=\alpha+\beta$, as with a single investor. The first order condition with respect to $m_{1}$ simplifies to $m_{1}=\frac{k_{1}}{k_{2}+k_{1}} m$, and the comparative statics are

$$
\frac{\partial t_{1}^{*}}{\partial k_{1}}=\frac{\partial t_{1}^{*}}{\partial k_{2}}=\frac{\partial t_{2}^{*}}{\partial k_{1}}=\frac{\partial t_{2}^{*}}{\partial k_{2}}=0, \text { and } \frac{\partial m_{1}^{*}}{\partial k_{1}}=\frac{k_{2}}{\left[k_{2}+k_{1}\right]^{2}} m>0
$$

The problem of investor $i, i=1,2$ at the first stage is

$\max _{k_{i}} \pi_{i}=\left(1-t_{i}\right) k_{i}^{\alpha} m_{i}{ }^{\beta} z_{i}^{\gamma}-r k_{i}=\gamma k_{i}^{\alpha}\left[\frac{k_{i}}{k_{j}+k_{i}} m\right]^{\beta}\left[\left[\gamma^{2} k_{i}^{\alpha}\left[\frac{k_{i}}{k_{i}+k_{j}} m\right]^{\beta} w^{-1}\right]^{\frac{1}{\alpha+\beta}}\right]^{\gamma}-r k_{i}$

for $i, j=1,2$, and $i \neq j$. The corresponding first order conditions are

$\gamma^{\frac{2-\alpha-\beta}{\alpha+\beta}} w^{-\frac{1-\alpha-\beta}{\alpha+\beta}} m^{\frac{\beta}{\alpha+\beta}}\left[\frac{\alpha}{\alpha+\beta}\left[\frac{k_{i}}{k_{i}+k_{j}}\right]^{\frac{\beta}{\alpha+\beta}} k_{i}^{\frac{\alpha}{\alpha+\beta}-1}+k_{i}^{\frac{\alpha}{\alpha+\beta}} \frac{\beta}{\alpha+\beta}\left[\frac{k_{i}}{k_{i}+k_{j}}\right]^{\frac{\beta}{\alpha+\beta}-1} \frac{k_{j}}{\left(k_{i}+k_{j}\right)^{2}}\right]=r$.

Note that $\frac{\partial^{2} \pi_{i}}{\partial k_{i} \partial k_{j}}<0$, which implies that the investors' reaction functions are downward sloping and the symmetric equilibrium is unique. Using symmetry, we have

$$
\gamma^{\frac{1+\gamma}{\alpha+\beta}} w^{-\frac{\gamma}{\alpha+\beta}} m^{\frac{\beta}{\alpha+\beta}}\left[\frac{\alpha}{\alpha+\beta}\left[\frac{k_{i}}{2 k_{i}}\right]^{\frac{\beta}{\alpha+\beta}} k_{i}^{\frac{\alpha}{\alpha+\beta}-1}+k_{i}^{\frac{\alpha}{\alpha+\beta}} \frac{\beta}{\alpha+\beta}\left[\frac{k_{i}}{2 k_{i}}\right]^{\frac{\beta}{\alpha+\beta}-1} \frac{k_{i}}{\left(2 k_{i}\right)^{2}}\right]=r
$$

which can be solved for $k_{i}^{*}=\frac{A}{2}\left[\frac{\alpha}{\alpha+\beta}+\frac{\beta}{\alpha+\beta} \frac{1}{2}\right]^{\frac{\alpha+\beta}{\beta}}$.

We can now compare the total investment in the competing investor case to the investment in the single investor case. Total investment in the competing investor and the single investor case are

$$
2 k_{i}^{*}=A\left[\frac{\alpha}{\alpha+\beta}+\frac{\beta}{\alpha+\beta} \frac{1}{2}\right]^{\frac{\alpha+\beta}{\beta}} \text {, and } k_{s}^{*}=A\left[\frac{\alpha}{\alpha+\beta}\right]^{\frac{\alpha+\beta}{\beta}} \text {, }
$$

respectively. Since $\frac{\beta}{\alpha+\beta} \frac{1}{2}>0$ we have $2 k_{i}^{*}>k_{s}^{*}$, i.e. total investment in the competing investor case is always higher. 
Figure 1: Parameter combinations which fulfill (A8), i.e. for which total investment without commitment and competing investors is higher than in the commitment case (black area)

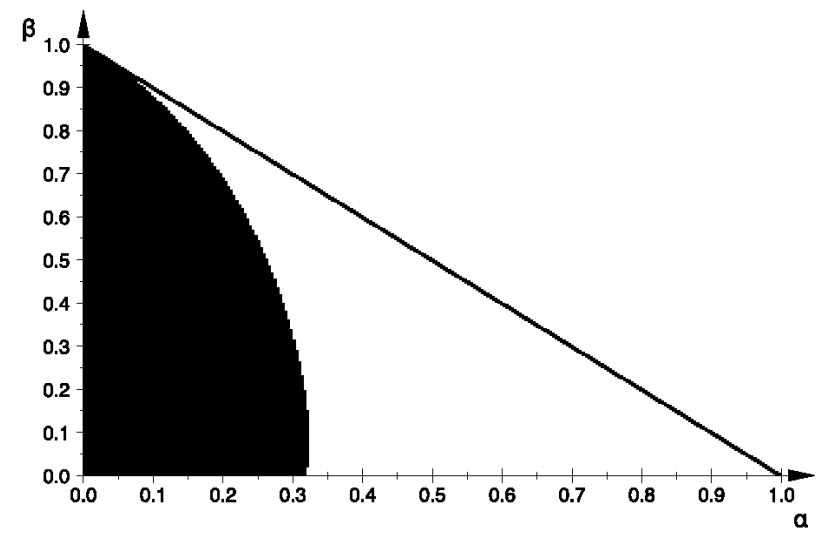

\subsection{Proof of Proposition 5}

Proposition 1 established that there is no difference in total investment, production and tax revenues between the single investor case and the case with two competing investors. We here compare this commitment outcome with the case of two competing investors without commitment. Let $B \equiv m w^{-\frac{\gamma}{\beta}} r^{-\frac{\alpha+\beta}{\beta}} \gamma^{\frac{\gamma}{\beta}}$. From (A3) and (A7) investment with and without commitment (the latter with two competing investors) equals

$$
2 k_{i}^{*}=B \gamma^{\frac{1}{\beta}}\left[\frac{\alpha}{\alpha+\beta}+\frac{\beta}{\alpha+\beta} \frac{1}{2}\right]^{\frac{\alpha+\beta}{\beta}}, \text { and } 2 \bar{k}_{i}^{*}=\bar{k}_{s}^{*}=B(1-\beta)^{\frac{1}{\beta}} \alpha^{\frac{\alpha+\beta}{\beta}} \text {, }
$$

respectively. Total investment without commitment and competing investors will therefore be higher than investment under commitment if

$$
\left[\frac{2 \alpha+\beta}{2 \alpha(\alpha+\beta)}\right]^{\alpha+\beta}>\frac{1-\beta}{1-\alpha-\beta}
$$

Since inequality (A8) cannot be solved analytically, we rely on simulations to illustrate the conditions under which investment will be higher without commitment and competing investors relative to the commitment case. This is illustrated in Figure 1 and shows how this typically depends on the importance of the domestic resource as a factor of production.

Finally, we show by example that tax revenues in the competing investor case without commitment can be higher than tax revenues in the commitment case. To this end, it is useful to express the tax base as a function of the invested capital stock in both cases. 
Tax revenues with and without commitment are, respectively,

$$
\begin{aligned}
& \bar{T}=\bar{t} 2 \bar{k}_{i}^{\alpha}\left[\frac{m}{2}\right]^{\beta}\left[(1-\bar{t}) \gamma\left[\frac{m}{2}\right]^{\beta}\left[\frac{\bar{k}_{s}}{2}\right]^{\alpha} w^{-1}\right]^{\frac{\gamma}{\alpha+\beta}}=\bar{t}(1-\bar{t})^{\frac{\gamma}{\alpha+\beta}} \bar{D}, \text { and } \\
& T=2 t k_{i}^{\alpha}\left[\frac{m}{2}\right]^{\beta} z_{i}^{\gamma}=2 t k_{i}^{\alpha}\left[\frac{m}{2}\right]^{\beta}\left[\left(1-t_{i}\right) \gamma k_{i}^{\alpha} m_{i}^{\beta} w^{-1}\right]^{\frac{\gamma}{\alpha+\beta}}=t(1-t)^{\frac{\gamma}{\alpha+\beta}} D
\end{aligned}
$$

with $\bar{D} \equiv 2\left[\frac{\bar{k}_{s}}{2}\right]^{\alpha}\left[\frac{m}{2}\right]^{\beta}\left[\gamma\left[\frac{\bar{k}_{s}}{2}\right]^{\alpha}\left[\frac{m}{2}\right]^{\beta} w^{-1}\right]^{\frac{\gamma}{\alpha+\beta}}$, and $D \equiv 2 k_{i}^{\alpha}\left[\frac{m}{2}\right]^{\beta}\left[\gamma k_{i}^{\alpha}\left[\frac{m}{2}\right]^{\beta} w^{-1}\right]^{\frac{\gamma}{\alpha+\beta}}$, respectively. If total investment is higher in the absence of commitment, i.e. if $k_{i}^{*}>\frac{\bar{k}_{s}^{*}}{2}$, which is the case if inequality (A8) holds, this implies $D>\bar{D}$. Accordingly, $T>\bar{T}$ whenever (A8), and additionally

$$
t(1-t)^{\frac{\gamma}{\alpha+\beta}}>\bar{t}(1-\bar{t})^{\frac{\gamma}{\alpha+\beta}}, \text { or } \frac{\alpha+\beta}{\beta}>\left[\frac{(1-\beta)}{(1-\alpha-\beta)}\right]^{\frac{\gamma}{\alpha+\beta}}
$$

holds, where we have substituted $\bar{t}^{*}=\beta$ and $t^{*}=\alpha+\beta$. Now let $\alpha=0.2, \beta=0.3, \gamma=0.5$, such that this inequality (A9) is true, and also the inequality (A8) holds. Thus, $T>\bar{T}$ for this parameter constellation.

\section{References}

[1] Bhattacharyya, S. and R. Hodler (2010) Natural Resources, Democracy and Corruption, European Economic Review 54, 608-621.

[2] Bohn, H. and R. Deacon (2000) Ownership Risk, Investment, and the Use of Natural Resources, American Economic Review 90, 526-549.

[3] Bonfatti, R. (2009) Foreign Influence and the Chinese African Trade in Natural Resources, London School of Economics, mimeo.

[4] Brautigam, D. (2009) The Dragon's Gift, Oxford: Oxford University Press.

[5] Bremmer, I. and R. Johnston (2009) The Rise and Fall of Resource Nationalism, Survival $51(2), 149-158$.

[6] Cooley, A. (2012) Great Games, Local Rules, Oxford: Oxford University Press.

[7] Doyle, C. and S. van Wijnbergen (1994) Taxation of Foreign Multinationals: A Sequential Bargaining Approach to Tax Holidays, International Tax and Public Finance 1, 211-225.

[8] Eaton, J. and M. Gersovitz (1983) Country Risk: Economic Aspects, in: R. J. Herring (ed.), Managing international risk, Cambridge: Cambridge University Press, 75-108.

[9] Economy, E. and M. Levi (2014) By All Means Necessary: How China's Resource Quest is Changing the World, Washington: Council on Foreign Relations. 
[10] Engel, E. and R. Fischer (2010) Optimal Resource Extraction Contracts under Threat of Expropriation, in: W. Hogan and F. Sturzenegger (eds), The Natural Resources Trap, Cambridge: MIT-Press, 161-195.

[11] Gustafson, T. (2012) Wheel of Fortune: The Battle for Oil and Power in Russia, Cambridge: Belknap Press.

[12] Halper, S. (2010) The Beijing Consensus, New York: Basic Books.

[13] Hogan, W., F. Sturzenegger and L. Tai (2010) Contracts and Investment in Natural Resources, in: W. Hogan and F. Sturzenegger (eds), The Natural Resources Trap, Cambridge: MIT-Press, 1-43.

[14] Janeba, E. (2000) Tax Competition when Governments Lack Commitment: Excess Capacity as a Countervailing Threat, American Economic Review 90, 1508-1519.

[15] Joffé, G. P. Stevens, T. George, J. Lux and C. Searle (2009) Expropriation of Oil and Gas Investments: Historical, Legal and Economic Perspectives, Journal of World Energy Law and Business 2 (1), 3-23.

[16] Kessing, S., K. A. Konrad, C. Kotsogiannis (2006) Federalism, Tax Autonomy and the Limits of Cooperation, Journal of Urban Economics, 59(2), 317-329.

[17] Kessing, S., K. A. Konrad, C. Kotsogiannis (2007) Foreign Direct Investment and the Dark Side of Decentralization, Economic Policy 49, 5-70.

[18] Kessing, S., K. A. Konrad, C. Kotsogiannis (2009) Federalism, Weak Institutions and the Competition for Foreign Direct Investment, International Tax and Public Finance 16, 105123.

[19] Konrad, K. A., K. E. Lommerud (2001) Foreign Direct Investment, Intra-Firm Trade and Ownership Structure, European Economic Review 45, 475-494.

[20] Konrad, K. A. (2009) Strategy and Dynamics in Contests, Oxford: Oxford University Press.

[21] Manzano, O., F. Monaldi (2010) The Political Economy of Oil Contract Renegotiation in Venezuela, in: W. Hogan, F. Sturzenegger (eds), The Natural Resources Trap, Cambridge: MIT-Press, 409-466.

[22] Maurer, N. (2013) The Empire Trap, Princeton: Princeton University Press.

[23] Moran, T. (2010) China's Strategy to Secure Natural Resources, Washington: Peterson Institute.

[24] Robinson, J., R. Torvik and T. Verdier (2006) Political Foundations of the Resource Curse, Journal of Development Economics 79, 447- 468.

[25] Sachs, J. and A. Werner (2001) The curse of natural resources, European Economic Review $45,827-838$.

[26] Schnitzer, M. (1999) Expropriation and Control Rights: A Dynamic Model of Foreign Direct Investment, International Journal of Industrial Organization 17, 1113-1137.

[27] Shambaugh, D. (2013) China Goes Global, Oxford: Oxford University Press.

[28] Stevens, P., J. Koorooshy, G. Lahn and B. Lee (2013) Conflict and Coexistence in the Extractive Industries, Chatham House Report, London: Chatham House. 
[29] Stroebel, J. and A. van Benthem (2013) Resource Extraction Contracts under Threat of Expropriation: Theory and Evidence, Review of Economics and Statistics 95, 1622-1639.

[30] Svensson, J. (1998) Investment, Property Rights and Political Instability: Theory and Evidence, European Economic Review 42, 1317-1341.

[31] Thomas, J., T. Worrall (1994) Foreign Direct Investment and the Risk of Expropriation, Review of Economic Studies 61, 1-108.

[32] Tomz, M. and M. Wright (2010) Sovereign Theft: Theory and Evidence about Sovereign Default and Expropriation, in: W. Hogan and F. Sturzenegger (eds), The Natural Resources Trap, Cambridge: MIT-Press, 69-110.

[33] Venn, F. (1986) Oil Diplomacy in the Twentieth Century, Houndsmill: Macmillan.

[34] World Bank (2009) Global Economic Prospects: Commodities at the Crossroads, Washington: World Bank.

[35] Yergin, D. (1991) The Prize, New York: Simon and Schuster. 